\title{
Arbitrabilidad objetiva: ¿Qué se puede y qué no se puede someter a arbitraje nacional según las fuentes colombianas de derecho?*
}

\author{
Objective Arbitrability: What Can Be and What Cannot be Submitted to Domestic Arbitration According to the \\ Colombian Sources of Law?
}

\author{
Juan Carlos Naizir Sistac a \\ Universidad Externado de Colombia, Colombia \\ juan.naizir@uexternado.edu.co \\ ORCID: http://orcid.org/0000-0002-5820-6293
}

DOI: https://doi.org/10.11144/Javeriana.vj139.aoqp

\author{
Recepción: 24 Julio 2019 \\ Aceptación: 29 Agosto 2019 \\ Fecha de publicación: 30 Diciembre 2019
}

\section{Resumen:}

Este artículo tiene por objeto estudiar la arbitrabilidad objetiva en el arbitraje nacional o doméstico en Colombia y proponer un catálogo o lista de asuntos que no son arbitrables con origen en la propia ley, en las varias decisiones que han proferido las cortes y la doctrina. Adicionalmente, se comentan ciertas áreas o temas que, aunque sean arbitrables, actualmente han resultado ser controversiales para el conocimiento de los árbitros. Luego de identificar y estudiar los asuntos que no son arbitrables en Colombia, para luego referirnos a ciertos asuntos puntuales que pueden ser sometidos a arbitraje —y que vale la pena destacar-, se concluye que, fruto de la libertad de la ley, se ha construido una lista de asuntos no arbitrables en Colombia. Esta lista en ningún momento pretende ser limitativa ni mucho menos taxativa, pero reflejan la evolución que ha tenido el legislador y las cortes en una construcción continua. Para la elaboración se ha empleado el método dogmático de investigación jurídica, que tiene en cuenta las disposiciones legales, la doctrina y la jurisprudencia de las altas Cortes en Colombia.

Palabras clave: Arbitraje, arbitrabilidad, arbitrabilidad objetiva, orden público, mecanismos alternativos de solución de conflictos.

\begin{abstract}
:
This article aims to study objective arbitrability in domestic arbitration in Colombia. This article proposes a catalog or list of matters that are not arbitrable originating in the law itself, in the various decisions that the courts and doctrine have uttered. In addition, this text comments on particular areas or topics that, although arbitrable, have proved currently controversial for the arbitrators' knowledge. After identifying and studying the issues that are not arbitrable in Colombia and then refer to certain specific issues that may be submitted to arbitration (that are worth mentioning), it is concluded that, as a result of the freedom of the law, a list of non-arbitrable matters in Colombia has been built. This list at no time is intended to be limiting or much less taxative, but that reflect the evolution that the legislator and the courts have had in its continuous construction. For the elaboration of this list, the dogmatic method of legal investigation has been used, which takes into account the legal provisions, doctrine and jurisprudence of the High Courts in Colombia.
\end{abstract}

Keywords: Arbitration, arbitrability, objective arbitrability, public order, alternative dispute resolution mechanisms.

\section{Introducción}

El arbitraje es uno de los mecanismos alternativos de solución de controversias, además de ser uno de los mecanismos preferidos como método hetero compositivo para solucionar conflictos ${ }^{[1]}$. Sin embargo, no tiene la libertad absoluta en nuestra legislación para solucionar la totalidad de los conflictos que se ocasionen entre los particulares. Adicional a las características propias del arbitraje que moldean este mecanismo y que lo delimitan para que no se convierta en otra de las figuras jurídicas imperantes en nuestro ordenamiento jurídico, la arbitrabilidad, en sus facetas objetiva y subjetiva, también limitan al arbitraje dentro de las áreas en

Notas de autor

\footnotetext{
${ }^{a}$ Autor de correspondencia. Correo electrónico: juan.naizir@uexternado.edu.co
} 
las que puede operar. Este artículo abordará el tema de la arbitrabilidad objetiva en Colombia desde el punto de vista de la regulación normativa, pero también, desde una posición igualmente protagónica realizada por el legislador y las altas cortes, quienes, con ayuda de la doctrina, han fijado los linderos de las materias o temas que pueden ser sometidos a un tribunal arbitral.

La finalidad de este artículo es el de estudiar la arbitrabilidad objetiva en el arbitraje nacional o doméstico en Colombia al establecer y examinar los criterios de arbitrabilidad objetiva imperante en nuestra legislación. Asimismo, se busca identificar y estudiar los asuntos o temas que no son arbitrables en Colombia, para luego referirnos a ciertos asuntos puntuales que pueden ser sometidos a arbitraje y que valen la pena destacar. En la primera parte se revisarán los nexos entre arbitraje y la arbitrabilidad, para luego pasar a examinar la evolución normativa de la arbitrabilidad objetiva en el arbitraje nacional. Luego, se tratará sobre los asuntos que no son arbitrables en Colombia conocido bajo el término de arbitrabilidad objetiva negativa, y finalizará con ciertos asuntos puntuales que pueden ser sometidos a arbitraje o arbitrabilidad objetiva positiva.

\section{El arbitraje y la arbitrabilidad}

\section{La Corte Constitucional definió el concepto de arbitraje como}

"la derogación que hacen las partes involucradas en un conflicto o precaviendo su existencia, de la jurisdicción en cabeza del Estado y en favor de un particular (árbitro), quien queda investido de la facultad temporal de resolver con carácter definitivo y obligatorio, a través de una decisión denominada laudo arbitral, las diferencias que se susciten entre ellos." [2]

El legislador también se animó a definir el arbitraje en el artículo 111 de la Ley 446 de 1998 en donde se estableció que el arbitraje es "un mecanismo por medio del cual las partes involucradas en un conflicto de carácter transigible, defieren su solución a un tribunal arbitral, el cual queda transitoriamente investido de la facultad de administrar justicia, profiriendo una decisión denominada laudo arbitral" ${ }^{[3]}$.

La jurisprudencia, además de establecer una definición de arbitraje, también ha identificado las características que lo delimitan. En sentencia C-060 de 2001 precisó ciertas características de la institución arbitral en el ordenamiento colombiano al indicar que "El arbitramento es voluntario, temporal y excepcional.Además, reiteró que es una figura procesal, es decir, un procedimiento judicial, y como tal está sujeto a la estricta aplicación de las normas y principios que regulan esa clase de actuaciones"[ ${ }^{\text {[4] }}$.

Estas características distintivas del arbitraje en Colombia como voluntario, temporal, excepcional y como figura procesal fueron estudiadas detalladamente en la sentencia C-330 de 2000. Iniciemos con la primera de ellas, el carácter voluntario del arbitraje. La decisión de no acudir a los jueces ordinarios para en su lugar ventilar las disputas de una relación jurídica en un tribunal arbitral debe originarse de un acuerdo previo de carácter voluntario y libre efectuado por los contratantes. Resulta ser la voluntad de las partes en conflicto la que faculta a los árbitros para dirimir el conflicto y la que en ultimas ubica el arbitraje como mecanismo que desplaza a la jurisdicción ordinaria en el conocimiento de ciertos asuntos ${ }^{[5]}$.

El carácter temporal parte de la base que la naturaleza arbitral no puede ser indefinida en el tiempo, es meramente transitoria, limitada en el tiempo, a la resolución del conflicto específico que las partes deciden llevar ante el tribunal. Las facultades judiciales que tienen los árbitros cuando ejercen como tal deben estar limitadas en el tiempo, de lo contrario "se crearía una jurisdicción paralela a la ordinaria que, con grave perjuicio del orden público, debilitaría la estructura estatal y menoscabaría la función pública de administrar justicia." ${ }^{[6]}$.

En nuestro ordenamiento jurídico el arbitraje tiene la característica de ser una figura procesal. Cuando el artículo 116 de la Constitución le confiere a los particulares la función de administrar justicia en calidad de árbitros, los faculta para solucionar conflictos jurídicos entre las partes aplicando la constitución y las leyes. De modo que los árbitros administran justicia como lo hacen los demás jueces pertenecientes a la rama 
judicial. La institución arbitral tiene un carácter de proceso en nuestro ordenamiento al garantizarle a las partes una serie de etapas y oportunidades para la discusión de los argumentos y para la valoración de las pruebas que se aporten o practiquen ${ }^{[7]}$. Otro aspecto es la posibilidad que tienen los particulares de acordar las reglas de procedimiento que seguirán, bien sea directamente o por referencia a un Centro de Arbitraje salvo que una de las partes sea el Estado o una de sus entidades-, siempre dando cumplimiento a los principios constitucionales del debido proceso, derecho de defensa y la igualdad de las partes ${ }^{[8]}$. Las garantías del debido proceso aplicables a toda actuación judicial son de obligatorio cumplimiento en el proceso arbitral, ya que son mecanismos de solución de litigios, adicionales y alternativos al sistema ordinario que no pueden desconocer derechos constitucionales fundamentales como el debido proceso ${ }^{[9]}$.

Finalmente, la excepcionalidad del arbitraje como una más de sus características encuentra fundamento debido a que existen limitaciones materiales para que los particulares solucionen algunos conflictos, si se tiene en cuenta que no todo problema jurídico puede ser objeto de un laudo. A pesar de que voluntariamente las partes hayan designado árbitros para solucionar un conflicto, el legislador ha limitado las materias objeto de arbitraje, ya que en su consideración existen bienes jurídicos cuya disposición no puede dejarse al arbitrio de un particular, así sea que estén investidos temporalmente del poder jurisdiccional ${ }^{[10]}$. La equiparación de los funcionarios del Estado y ciertos ciudadanos para administrar justicia no puede ser absoluta en opinión del legislador, por lo que ha optado por limitar las materias o los temas en conflicto que pueden ser objeto de arbitraje ${ }^{[11]}$. La Corte Constitucional ha sostenido que el principio de seguridad jurídica conduce a que ciertos asuntos deban obligatoriamente ser ventilados en la jurisdicción ordinaria, es decir, la limitación de los temas que pueden ser objeto de arbitraje está sustentado en este principio, lo que, en última instancia, se traduce en el concepto de arbitrabilidad.

En este sentido, la arbitrabilidad o la delimitación de los temas que pueden ser objeto de laudo arbitral fue tratado en la sentencia T-057 de 1995, al decir que

"La colaboración prestada por los particulares en la administración de justicia tiene claro fundamento en la Constitución. Sin embargo, dicha colaboración, en el ámbito jurisdiccional, tiene carácter transitorio y excepcional. En primer término, [...] el arbitraje sólo puede tener por objeto asuntos que por su naturaleza sean susceptibles de dicho trámite, y es evidente que no todos lo son. No todo asunto de competencia de los jueces ordinarios, en consecuencia, puede ser trasladado a la justicia arbitral".[12]

A grandes rasgos "El término arbitrabilidad puede ser definido como la susceptibilidad que tiene una disputa de ser resuelta por medio de arbitraje." ${ }^{[13]}$. El concepto de arbitrabilidad fue abordado por la Corte Constitucional en sentencia SU-174 de 2007 al indicar que

"La arbitrabilidad es el criterio que se ha de aplicar para establecer la vocación que tienen determinados asuntos de ser objeto de decisión por un tribunal de arbitramento, así como la posibilidad de ciertos sujetos de acudir a este mecanismo de resolución de conflictos. Proporciona parámetros para identificar los límites a la voluntad de las partes que configura el tribunal arbitral, al determinar qué tipo de controversias pueden someterse a arbitraje (arbitrabilidad objetiva), y quiénes pueden hacer uso de este mecanismo (arbitrabilidad subjetiva)."[14]

Tradicionalmente la doctrina ha dividido en dos clases la arbitrabilidad, por razón de las personas involucradas. La primera, rationae personae o subjetiva se refiere a controversias en las que ciertos individuos o entidades son considerados incapaces para facultar sus disputas a los árbitros según normas legales que lo prohíben o que establecen condiciones para ello. La segunda, de acuerdo con las materias comprendidas \# rationaemateriae u objetiva\# se refiere a que, si el contenido del tema puede ser objeto de arbitraje, es decir, se busca determinar las materias objeto de reserva de los jueces nacionales por mandato del legislador ${ }^{[15]}$. Dicho de otra manera, la arbitrabilidad puede ser vista desde dos ópticas, la arbitrabilidad objetiva que examina las materias o los temas que pueden ser susceptibles de arbitraje, teniendo en cuenta los asuntos que los jueces 
permanentes de la rama judicial deben siempre conocer; mientras que la arbitrabilidad subjetiva identifica a las personas que están facultadas para nombrar árbitros y someter su disputa a estas.

\section{Evolución normativa de la arbitrabilidad objetiva en el arbitraje nacional}

El marco normativo que regulaba la materia arbitral hace algún tiempo era el contenido en el numeral 3 del artículo 13 de la Ley 270 de 1996, Estatutaria de la Administración de Justicia, que establecía:

"Artículo 13: Ejercen función jurisdiccional, de acuerdo con lo establecido en la Constitución Política:

3. Los particulares actuando como conciliadores o árbitros habilitados por las partes, en asuntos susceptibles de transacción, de conformidad con los procedimientos señalados en la ley. Tratándose de arbitraje, las leyes especiales de cada materia establecerán las reglas del proceso, sin perjuicio de que los particulares puedan acordarlas. Los árbitros, según lo determine la ley, podrán proferir sus fallos en derecho o en equidad" ${ }^{\text {[16]. }}$

Lo contenido en la ley estatutaria antes mencionada fue incluida en la legislación ordinaria en el artículo 111 de la Ley 446 de 1998, que se refería al arbitraje de la siguiente manera:

"El arbitraje es un mecanismo por medio del cual las partes involucradas en un conflicto de carácter transigible, difieren su solución a un tribunal arbitral, el cual queda transitoriamente investido de la facultad de administrar justicia, profiriendo una decisión llamada laudo arbitral". [17]

Posteriormente, fue proferido el Decreto 1818 de $1998^{[18]}$ denominado estatuto de los mecanismos alternativos de solución de conflictos en el que se compilaron una serie de normas de la época dispersas en distintas leyes y decretos que tenían en común la regulación de diversos mecanismos alternativos de solución de conflictos, centralizando las normas de esta materia en una sola regulación.

En aquel momento, los mecanismos alternativos de solución de conflictos que surgen de la voluntad de las partes y cuyas decisiones o soluciones tienen efecto de cosa juzgada -tales como el arbitramento, la conciliación y la amigable composición- tenían como límite de conocimiento los asuntos o materias transables o transigibles ${ }^{[19]}$.

Posteriormente, el artículo 6 de la Ley 1285 de $2009^{[20]}$, por medio de la cual se reforma la Ley 270 de 1996 Estatutaria de la Administración de Justicia, expresamente modificó el numeral 3 del artículo 13 de la Ley 270 de 1996. El nuevo texto vigente es el siguiente:

"ARTÍCULO 6. Modifíquese el artículo 13 de la Ley 270 de 1996:

Artículo 13. Del ejercicio de la función jurisdiccional por otras autoridades y por particulares. Ejercen función jurisdiccional de acuerdo con lo establecido en la Constitución Política:

Los particulares actuando como conciliadores o árbitros habilitados por las partes, en los términos que señale la ley. Tratándose de arbitraje, en el que no sea parte el estado o alguna de sus Entidades, los particulares podrán acordar las reglas de procedimiento a seguir, directamente o por referencia a la de un Centro de Arbitraje, respetando, en todo caso los principios Constitucionales que integran el debido proceso." ${ }^{[21]}$

Con la más reciente reforma de la Ley 270 de 1996 o ley estatutaria de la administración de justicia, se indican los parámetros generales para que el legislador ordinario legisle acerca de la competencia de los mecanismos alternativos de solución de conflictos (MASC). De modo que, conforme con lo establecido en la ley estatutaria de la administración de justicia vigente, la competencia de los árbitros habilitados por las partes no está ligada o limitada a conceptos como transigible, derechos disponibles o susceptibles de transacción, como acontecía en la década de los años noventa. Por lo anterior, el legislador tiene la libertad de legislar para que los asuntos sometidos a arbitraje no tengan la antigua camisa de fuerza que limitaba a los asuntos susceptibles de transacción, simplemente por ley se puede indicar con plena libertad los asuntos que pueden ser sometidos a laudo arbitral. 
Finalmente, fue proferida la Ley 1563 de 2012 en la que se expide el estatuto de arbitraje nacional e internacional y se dictan otras disposiciones. En su artículo 1 se define el arbitraje y se indica la arbitrabilidad objetiva en Colombia para el arbitraje nacional o doméstico, al decir:

"ARTÍCULO 1.DEFINICIÓN, MODALIDADES Y PRINCIPIOS. El arbitraje es un mecanismo alternativo de solución de conflictos mediante el cual las partes defieren a árbitros la solución de una controversia relativa a asuntos de libre disposición o aquellos que la ley autorice."[22]

En la sección referente a arbitraje nacional de esta ley se establece que la arbitrabilidad objetiva tiene dos límites. Primero, para que los árbitros puedan conocer de un conflicto, la controversia debe ser relativa a asuntos de libre disposición. Segundo, el conocimiento de un asunto por los árbitros puede estar autorizado directamente por una ley.

Aparentemente, el primero de los limites antes mencionados podría significar una evolución sobre la materia arbitral. Sin embargo, visto con mayor detenimiento, los "asuntos de libre disposición" que indica nuestra ley podrían reflejar lo que antiguamente se denominaba un "conflicto de carácter transigible" en la Ley 446 de 1998. Vale la pena resaltar que en la ley estatutaria de administración de justicia no se incluye ningún límite para que el legislador indique como arbitrable los asuntos de libre disposición o de carácter transigible, lo que podría interpretarse como un retroceso al volver al sistema derogado del estatuto arbitral de los años noventa. En consecuencia, el legislador consideró que la amplia libertad otorgada en la ley estatutaria debía ser restringida con la inclusión de que la controversia sometida a arbitraje tenía que ser relativa a asuntos de libre disposición.

En el segundo de los límites acerca de que los asuntos de conocimiento de los árbitros pueden estar autorizados directamente por una ley, se consideró que resulta ser la verdadera novedad en este tema. La Ley 1563 de 2012 no solo se desmarcó de la arbitrabilidad objetiva vinculada con los asuntos de libre disposición, sino que, adicionalmente y de forma independiente, señala que pueden existir asuntos sometidos a arbitraje cuando el legislador indique con una ley el conocimiento para los árbitros. Más aun, lo que el legislador indique a través de una ley para que ser sometido a arbitraje puede ser un asunto que no sea de libre disposición o de carácter transigible. Dicho de otra manera, el estatuto arbitral recoge lo establecido en la ley estatutaria y faculta al legislador para que disponga lo que puede ser arbitrable o sometido a arbitraje sin tener en cuenta lo transigible o disponible del asunto en conflicto, basta que el legislador lo autorice por ley.

Ciertamente, la exposición de motivos de la Ley 1563 de 2012 recoge lo explicado anteriormente, al decir que

"establece el proyecto de ley una ampliación de los asuntos arbitrables. En efecto, de aprobarse el Proyecto de Ley quedarín sujetos a la decisión de los árbitros no solo aquellos asuntos que por su naturaleza sean transigibles, sino también los que por ley se defina que puedan ser dirimidos por el arbitraje, sean o no de carácter transigible." ${ }^{[23]}$

Compartimos la apreciación del profesor Hernán Fabio López cuando afirma que "de esta manera se establece que es viable en futuras reformas permitir que los árbitros puedan conocer y decidir asuntos que no versen sobre derechos disponibles, pero mientras esa modificación no se presente, únicamente a estos se circunscribe la jurisdicción de los árbitros" ${ }^{[24]}$. De este modo, el estatuto arbitral le abre la posibilidad para que el legislador profiera leyes en las que el tema en conflicto pueda ser resuelto a través de arbitraje, sin importar si se trata de asuntos de libre disposición o no. Por ejemplo, en el evento en que el legislador expida una ley que le otorga la posibilidad para que sea sometido a la decisión de los árbitros y el asunto no es disponible, consideraría que esta hipotética ley no tendría inconveniente ya que el estatuto arbitral habilita esta posibilidad y, además, la ley estatutaria de la administración de justicia luego de la reforma también lo faculta.

Finalmente, la arbitrabilidad objetiva en el arbitraje nacional o doméstico y su regulación en el estatuto arbitral que ha sido lo que se ha venido examinando es totalmente distinto al arbitraje obligatorio. En el 
arbitraje obligatorio se excluye la posibilidad de que un asunto sea conocido por los jueces permanentes de la rama judicial y, por lo tanto, se vuelve obligatorio que sean los árbitros los encargados de conocer sobre determinado asunto. Ya tratado el tema de las características del arbitraje, encontramos que, cuando es obligatorio, incumple las características de ser voluntario y temporal que le son propias a la figura arbitral, además de limitar el acceso a la administración de justicia.

\section{Asuntos que no son arbitrables en Colombia. Arbitrabilidad objetiva negativa}

La arbitrabilidad objetiva no solamente puede verse desde un punto de vista doméstico del país, también tiene efectos para establecer el orden público en Colombia de cara al arbitraje internacional. A nivel internacional existen también criterios para esbozar la arbitrabilidad objetiva de cada país para definir los parámetros de lo que es considerado el orden público y el reconocimiento y ejecución del laudo arbitral.

A propósito de este tema, la Ley Modelo de la UNCITRAL para arbitraje comercial internacional en su artículo 36 indica que sólo se podrá denegar el reconocimiento o la ejecución de un laudo arbitral, cualquiera que sea el país en que se haya dictado, cuando el tribunal compruebe i) que, según la ley de este Estado, el objeto de la controversia no es susceptible de arbitraje; o ii) que el reconocimiento o la ejecución del laudo serían contrarios al orden público de este Estado.

El estatuto arbitral en Colombia establece criterios para delimitar la arbitrabilidad objetiva, controversias relativas a asuntos de libre disposición o aquellos que la ley autorice. Sin embargo, se han hecho esfuerzos para definir en una lista contenida en la ley para identificar los asuntos arbitrables. Por ejemplo, al interior de la comisión para la expedición del estatuto arbitral se propuso incluir la tal mencionada lista de asuntos arbitrables, que decía

\footnotetext{
"Conflicto de carácter arbitrable. Se entiende que es de carácter arbitrable toda diferencia o conflicto de naturaleza jurídica que verse sobre asuntos de libre disposición y de cualquier otra materia, con la excepción de los siguientes conflictos que constituyen los únicos prohibidos por la ley: a) los relacionados con el estado civil de las personas. B) los relativos a derechos ajenos o que no existen. C) los relacionados con los delitos, con excepción de la acción civil que nace del delito. D) los relativos con obligaciones alimentarias. E) los asuntos que versen sobre alimentos futuros. F) los relacionados con derechos políticos o derechos que están fuera del comercio" ${ }^{[25]}$.
}

A pesar de que los asuntos consignados en esta lista efectivamente no pueden ser objeto de arbitraje en Colombia, existen y existirán otros que no están en la lista y que tampoco pueden ser arbitrables.

Resulta muy tentador catalogar o enlistar los asuntos en la propia ley arbitral que no pueden ser sometidos a arbitraje en Colombia, pero el tiempo nos revela que lo más saludable y la postura que le brinda libertad al legislador y a las cortes, en especial a la Corte Constitucional, para que fruto del estudio de un caso concreto indique la arbitrabilidad o no de determinado asunto es precisamente no tener en la ley una lista de asuntos no arbitrables. La evolución y dinámica jurisprudencial con el estudio de casos concretos resulta ser el mejor aliado para definir la arbitrabilidad objetiva en Colombia, así como la permanente actualización de los asuntos que pueden o no ser objeto de arbitraje. Por esta razón, fruto de esta investigación se ha construido una lista de asuntos no arbitrables en Colombia que en ningún momento pretende ser limitativa ni mucho menos taxativa. Resulta ser una recopilación explicada de asuntos no arbitrables que pueden servir de criterio para que en un futuro se amplíe o se limite la lista que permanentemente seguirán en construcción por el legislador y las cortes. Así las cosas, la jurisprudencia en Colombia, ciertas normas puntuales y la doctrina nos indican el catálogo de asuntos que no son arbitrables en Colombia. 


\section{Estado civil de las personas}

La Corte Constitucional ha sido reiterativa desde sus inicios en indicar que los conflictos relacionados con el estado civil de las personas no pueden ser susceptibles de arbitraje. En la sentencia C-294 de 1995 establece que están "excluidas del arbitramento cuestiones tales como las relativas al estado civil, o las que tengan que ver con derechos de incapaces, o derechos sobre los cuales la ley prohíba a su titular disponer." ${ }^{[26]}$.

En esta misma sentencia la Corte fundamenta su decisión en lo regulado sobre esta materia en el código civil. Se excluye del pacto arbitral conforme con el estatuto arbitral a todas aquellas controversias que versen sobre cuestiones no susceptibles de libre disposición, o entre incapaces. Al respecto, en el artículo 2470 del Código Civil establece que "no puede transigir sino la persona capaz de disponer de los objetos comprendidos en la transacción". Finaliza con lo contenido en el artículo 2473 del Código Civil acerca de que "no se puede transigir sobre el estado civil de las personas". Por lo anterior, resulta muy claro que aun cuando los asuntos transigibles y de libre disposición un criterio para la arbitrabilidad objetiva en Colombia en el arbitraje nacional, los asuntos que no son transigibles como lo indica la misma norma del código civil, no podrán ser susceptibles de arbitraje nacional.

Reiterando esta posición, la Corte en sentencia C-242 de 1997 indica que "no todos los asuntos pueden ser sometidos genéricamente a su conocimiento, como, por ejemplo, los relacionados con el estado civil de las personas, ya que detenta un carácter transitorio para su realización." ${ }^{27]}$. En esta ocasión, la Corte también descarta que los árbitros deban conocer del estado civil de las personas motivado en la característica de transitoriedad propia del arbitraje.

\section{Derechos de incapaces y derechos que se prohíbe a los titulares disponer}

La Corte Constitucional establece que están excluidas del arbitramento "las que tengan que ver con derechos de incapaces, o derechos sobre los cuales la ley prohíba a su titular disponer" ${ }^{\text {"[28] }}$. En esta providencia la Corte recuerda que el arbitraje siempre ha tratado sobre asuntos susceptibles de transacción, por lo que decía la ley arbitral vigente hoy sobre asuntos de libre disposición, y que ocurran entre personas legalmente capaces.

El pacto arbitral es un negocio jurídico en el que las partes contraen la obligación de someter a arbitraje las controversias que surjan o puedan surgir sobre un determinado asunto, por lo que las partes deben cumplir con los requisitos establecidos en el artículo 1502 del Código Civil para que una persona se obligue con otra por un acto o declaración de voluntad ${ }^{[29]}$. El primero de estos requisitos es, precisamente, que la persona sea legamente capaz, es decir, que la persona tenga la capacidad legal de poderse obligar por sí misma y sin la autorización o ministerio de otra. De modo que la regulación establecida en las leyes civiles sobre capacidad de las partes se debe aplicar a quienes vayan a celebrar un contrato de arbitraje.

\section{Conjunto de derechos mínimos de los trabajadores en materia laboral}

El arbitraje como concepto que hemos explorado es distinto a la noción de arbitraje que se maneja en materia laboral. Puede que el arbitraje dentro de la concepción laboral cumpla con las características que hemos comentado, pero existen diferencias que lo alejan del arbitraje en materia comercial, civil o en la que interviene el Estado o alguna de sus entidades. El concepto de arbitraje obligatorio ha sido rechazado en innumerables ocasiones, pero en las normas laborales la clasificación de arbitraje obligatorio y voluntario es perfectamente admitido y aplicado. En líneas posteriores examinaremos las diferencias de ambos tipos de arbitraje en materia laboral, por ahora nos centraremos en el arbitraje voluntario que resuelve controversias 
originadas en el contrato de trabajo, llamados conflictos jurídicos que versan sobre la interpretación de un derecho ya existente.

La Corte Constitucional en la sentencia C-330 de 2000 subraya que en materia laboral, además de las garantías al debido proceso y al acceso a la administración de justicia, existen unos principios mínimos adicionales consagrados en la constitución como el

"reconocimiento de la igualdad de oportunidades para los trabajadores; la remuneración mínima, vital y móvil, proporcional a la cantidad y calidad de trabajo; la estabilidad en el empleo; la irrenunciabilidad a los beneficios mínimos establecidos en normas laborales; la atribución de facultades para transigir y conciliar sobre derechos inciertos; la aplicación de la situación más favorable al trabajador en caso de duda en la interpretación de las fuentes formales de derecho; y la primacía de la realidad sobre formalidades establecidas por los sujetos de las relaciones laborales, entre otros." [30]

La Constitución ha contribuido a que el derecho laboral este acorde con un orden social y económico justo y más cercano a la realidad ${ }^{[31]}$ al establecer derechos laborales fundamentales proferidos constitucionalmente, que deben ser protegidos por los jueces y que no pueden ser sujetos de disposición o transacción por las partes en conflicto, lo que los sustrae de la órbita arbitral.

El riesgo latente en materia laboral es que los acuerdos entre patrono y trabajador sean unos contratos de adhesión, con ello la utilización de la cláusula compromisoria como una imposición de la parte fuerte en la relación con un claro perjuicio de los derechos del otro y de su capacidad decisoria que trae consigo la invalidez por objeto ilícito. La relación laboral debería preservar las condiciones de igualdad, pero en realidad se trata de un vínculo de subordinación en el que la fuerza productiva la pone el trabajador al empleador, por lo que el nexo en la relación es una distribución asimétrica de fuerzas basado en el poder de ordenar materialmente la actividad de la otra y la capacidad económica para fijar la retribución del esfuerzo realizado $^{[32]}$. Como consecuencia, el empleador contará con holgados recursos económicos para hacer valer sus pretensiones, mientras que el otro participa en un proceso con limitaciones económicas y sociales para defender sus intereses. En conclusión, en el derecho individual del trabajo, el acceso a la administración de justicia y la desigualdad de las partes son factores que, de acuerdo con el principio de realidad imperante en laboral, imposibilitan la utilización del arbitraje en esta materia.

\section{Orden Público, Soberanía Nacional Y Orden Constitucional}

La Corte Constitucional fue enfática en excluir del arbitraje los asuntos que involucren el orden público, la soberanía nacional o el orden constitucional, asuntos que en razón de su naturaleza están reservados para el Estado, a través de sus distintos órganos ${ }^{[33]}$. Igualmente, fundamentó su posición en que no todo asunto de competencia de los jueces ordinarios puede ser de competencia para la justicia arbitral ${ }^{[34]}$.

Posteriormente, en otra sentencia, la Corte reiteró su posición sobre este tema al manifestar que "los árbitros no pueden pronunciarse sobre asuntos que involucran el orden público, la soberanía nacional o el orden constitucional, que están reservados por su naturaleza a la decisión de los órganos jurisdiccionales del Estado" ${ }^{[35]}$.

\section{Suspensión provisional de los efectos de los actos administrativos}

En el artículo 238 de la Constitución establece que "La jurisdicción de lo contencioso administrativo podrá suspender provisionalmente, por los motivos y con los requisitos que establezca la ley, los efectos de los actos administrativos que sean susceptibles de impugnación por vía judicial" ${ }^{36]}$. De esta forma, la propia Constitución indica que la jurisdicción de lo contencioso administrativo es la única que tiene la facultad de 
suspender provisionalmente los efectos de los actos administrativos y con ello excluye de toda posibilidad al arbitraje de su conocimiento.

En la sentencia C-1436 de 2000 la Corte afirma que la jurisdicción contencioso administrativa es la competente de forma exclusiva para pronunciarse sobre la legalidad de los actos administrativos ${ }^{[37]}$, el actuar el Estado en ejercicio de una función pública y en defensa del interés general, puesto que ambos son temas que no son susceptibles de disponibilidad y, por ello, quedan excluidos del arbitraje ${ }^{[38]}$. Como consecuencia, la jurisdicción de lo contencioso administrativo es la única que puede pronunciarse sobre la validez de sus actos, nunca por los árbitros ${ }^{[39]}$.

\section{Jurisdicción coactiva}

La Corte Constitucional, de forma general, señala que los árbitros podrían eventualmente ser competentes para conocer de procesos ejecutivos sin quebrantar la constitución, siempre que se establezcan las reglas para este tipo de proceso ${ }^{[40]}$. Actualmente, no se tienen las formas propias del juicio para el arbitraje en el proceso ejecutivo, por lo que sin esta regulación los árbitros no podrían conocer de este tipo de procesos. Dicho lo anterior, la Corte Constitucional establece una excepción absoluta para los procesos ejecutivos en conocimiento de los árbitros, los procesos de la jurisdicción coactiva ${ }^{[41]}$.

El cobro de deudas a favor del fisco sería el único proceso ejecutivo que no podría ser conocido por los árbitros, al ser una especie a la que se refiere el numeral 5 del artículo 268 de la Constitución. Al ser la Contraloría General de la Nación la entidad estatal encargada de ejercer la jurisdicción coactiva para el recaudo de los montos adeudados al estado colombiano fruto de la responsabilidad de la gestión fiscal según la Constitución, se podría interpretar que la voluntad de los constituyentes fue que de manera restrictiva un organismo del estado sea el competente para efectuar dicho recaudo de dineros públicos producto de este tipo de sanciones pecuniarias, excluyendo por ende la competencia de los árbitros.

\section{Derechos morales de autor y ciertas acciones de nulidad en propiedad industrial}

En el universo de la propiedad intelectual la gran mayoría de temas son susceptibles de ser sometidos a arbitraje, pero existe un asunto tanto en el derecho de autor como en la propiedad industrial que le esta negada a la justicia arbitral. En materia de derechos de autor se considera que los conflictos que se originen sobre derechos morales de los autores no podrán ser de conocimiento de árbitros. La Corte Constitucional en sentencia C-155 de 1998 estableció que los derechos morales de los autores son considerados un derecho fundamental y hacen parte de la integridad y personalidad del autor, lo que los convierte en irrenunciables $y$, como consecuencia, en derechos no disponibles ni transigibles ${ }^{[42]}$. Por consiguiente, siendo los derechos morales de los autores irrenunciables y no disponibles, no podrán los conflictos que de ellos surjan ser sometidos a conocimiento de árbitros.

En materia de propiedad industrial no pueden ser sometidos a arbitraje los conflictos relacionados con la validez de los derechos de patentes, marcas o diseños industriales. El Consejo de Estado resulta ser el ente competente para conocer de la acción de nulidad de patentes ${ }^{[43]}$, de la nulidad del certificado de registro de un dibujo o modelo si no son nuevos o si se refieren a alguna ventaja técnica ${ }^{[44]}$, así como de la acción de nulidad del certificado de una marca ${ }^{[45]}$. Adicionalmente, la Decisión 486 de 2000 de la Comunidad Andina de Naciones (CAN) establece que se debe indicar a una autoridad nacional competente de cada país para que tenga competencia para conocer de las nulidades citadas, en Colombia la autoridad es el Consejo de Estado ${ }^{[46]}$. 
Por lo anterior, las normas regionales de la CAN y la regulación interna de Colombia les imposibilitan a los tribunales arbitrales que conozcan de este tipo de controversias al conferirle competencia al Consejo de Estado para estas acciones de nulidad.

\section{Las Zonas de Interés de Desarrollo Rural, Económico y Social (Zidres)}

Con la expedición de la Ley 1776 de 2016 se crean y se desarrollan las Zonas de Interés de Desarrollo Rural, Económico y Social, denominadas "Zidres", con el fin de constituir un nuevo modelo de desarrollo económico regional en Colombia. Consisten en territorios con aptitud agrícola, pecuaria, forestal y piscícola identificados por la Unidad de Planificación Rural Agropecuaria (UPRA), que se establecen a partir de Planes de Desarrollo Rural Integral en un marco de economía formal y de ordenamiento territorial, soportados bajo parámetros de plena competitividad e inserción del recurso humano en un contexto de desarrollo humano sostenible, crecimiento económico regional, desarrollo social y sostenibilidad ambiental.

Con las Zidres se podrán utilizar bienes para la ejecución de proyectos productivos en el campo colombiano. De modo que, para la ejecución de los proyectos productivos se le podrá solicitar al Gobierno nacional la entrega en concesión, arrendamiento o cualquier otra modalidad contractual no traslaticia de dominio de bienes inmuebles de la nación ubicados en las Zidres, con el propósito de ejecutar los proyectos productivos que trata esta misma ley. Sin embargo, en el parágrafo 3 del artículo 13 de esta Ley 1776 de 2016 se prohíbe expresamente la existencia de pacto arbitral para dirimir las diferencias surgidas por causa o con ocasión del contrato celebrado, por lo que indica que los conflictos jurídicos surgidos serán debatidos y resueltos ante la jurisdicción competente ${ }^{[47]}$. Del mismo modo, en el artículo 15 de esta ley, al regular los aportes para la ejecución del proyecto aprobado por el Ministerio de Agricultura y Desarrollo Rural en las Zidres, indica que en el evento que los aportantes de los predios para el desarrollo del proyecto productivo tengan la condición de campesinos, mujer rural o trabajadores agrarios, no se permitirá la existencia de pacto arbitral con el fin de dirimir diferencias o conflictos, cuando haya lugar a ello. Se puede concluir que los eventos anteriores se convierten en una clara prohibición para que la justicia arbitral tenga competencia para resolver los asuntos antes descritos en las Zidres.

\section{Acciones de grupo o de clase}

En materia de acciones de grupo o clase cuya regulación se encuentra en la Ley 472 de 1998 la Corte Suprema de Justicia ha indicado que los tribunales de arbitramento no son competentes porque la sentencia que se profiera vincula a todas las personas que se encuentren en condiciones uniformes respecto de una misma causa que originó perjuicios individuales ${ }^{[48]}$. De lo anterior se puede entender que la exclusión del arbitraje no está relacionada con las materias que pueden ser objeto de esta acción, sino de la naturaleza de la sentencia que se profiere y de sus efectos en el plano arbitral. Adicionalmente, la Corte establece que es posible que un tribunal arbitral sea competente de una acción de grupo cuando el grupo está conformado únicamente por personas que han aceptado un pacto arbitral y una de estas personas o un grupo de ellos desea presentar una acción de grupo, por lo que los interesados deberán respetar y aplicar el pacto arbitral suscrito y presentar la acción de grupo ante un tribunal de arbitramento. Por ejemplo, en el arbitraje de Luis Alberto Duran contra el Banco de Colombia con laudo proferido el 30 de enero de 2004 en la Cámara de Comercio de Bogotá se tramitó excepcionalmente una acción de grupo dentro de un proceso arbitral. De todas formas, aparte de las consideraciones de la Corte, el trámite propio de la acción de grupo es considerada incompatible con el procedimiento arbitral al existir una serie de trámites subsiguientes luego de proferirse el laudo que resultan 
imposibles de cumplir ante la pérdida de competencia de los árbitros, pero que ante los jueces permanentes de la rama judicial no existe ningún inconveniente ${ }^{[49]}$.

\section{Asuntos puntuales para resaltar que pueden ser sometidos a arbitraje. Arbitrabilidad objetiva positiva}

La gran mayoría de los temas pueden ser sometidos a un tribunal arbitral en materia civil, comercial y cuando interviene el Estado o una de sus entidades, tal como lo hemos visto anteriormente, al aplicar los criterios de arbitrabilidad objetiva que dispone el estatuto arbitral y, además, sin perder de vista los asuntos que no son arbitrables en Colombia según la ley, la jurisprudencia de las cortes y la doctrina. En efecto, los límites de la arbitrabilidad objetiva resultan protagónicos para el arbitraje doméstico e internacional en Colombia, pero, de igual forma, vale la pena destacar ciertos temas que, aunque no pertenecen a dichos límites de la arbitrabilidad objetiva, pueden ser sometidos a arbitraje. Resulta oportuno destacarlo dado su manifiesto desarrollo histórico, normativo o simplemente un aspecto de un tema que bien ha tenido impacto en el ámbito del arbitraje nacional. A continuación, examinaremos unos temas que, aunque no hagan parte de los límites de la arbitrabilidad objetiva, consideramos que merecen ser examinados por su impacto en el tema de la arbitrabilidad.

\section{Proceso ejecutivo}

En el año 1995 se estudió por primera vez la competencia de los árbitros para conocer de los procesos ejecutivos con las sentencias C-294 y T-057 ambas de 1995, pero con decisiones opuestas. En la providencia C-294 de $1995^{[50]}$ la Corte inicia haciendo un estudio de las personas que pueden administrar justicia según el artículo 116 de la Constitución para luego examinar la arbitrabilidad del estatuto arbitral en su artículo primero de aquella época. La Corte Constitucional, después de haber revisado las limitaciones a la competencia de los árbitros, encuentra que no es admisible sostener que los asuntos que se ventilan, o podrían ventilarse, en el proceso de ejecución, están excluidos del proceso arbitral ${ }^{[51]}$. Sostiene que el proceso ejecutivo es, precisamente, el medio para conseguir el cumplimiento de las obligaciones civiles. Cuando se reúnen los requisitos establecidos por la ley procesal, dichas obligaciones cuyo cumplimiento puede exigirse ejecutivamente, son de contenido económico y están gobernadas por el principio de la autonomía de la voluntad $^{[52]}$. Concluye que las obligaciones exigibles en el proceso ejecutivo no han sido excluidas del proceso arbitral ni del mecanismo de la conciliación por el artículo 116 de la Constitución.

La Corte concluye que conforme con el artículo 116 de la Constitución, "los árbitros, habilitados por las partes, en los términos que determine la ley, pueden administrar justicia para decidir conflictos surgidos en torno a obligaciones exigibles ejecutivamente, así esté en trámite el proceso ejecutivo, o no haya comenzado aún." ${ }^{[53]}$. De lo anterior se puede desprender que no existe limitación alguna para que los árbitros conozcan de conflictos relacionados con las obligaciones que se exigen en el proceso ejecutivo, en especial, cuando se opone el ejecutado a las pretensiones de pago del ejecutante a través de las excepciones de mérito que esgrima aquel. En este escenario se dice que el proceso ejecutivo se torna en un proceso declarativo con el fin de dilucidar la existencia del título ejecutivo con todos sus requisitos y características ${ }^{[54]}$. Dicho de otra manera, los árbitros entrarían a conocer de las excepciones de mérito en contra del título ejecutivo presentado por el ejecutante para definir si se continua o no con el desarrollo del proceso ejecutivo en curso.

Adicionalmente a la situación antes mencionada, la Corte va más allá al comentar la hipótesis de la existencia de reglas de un arbitraje aplicable para un proceso ejecutivo. La Corte recuerda que 
"corresponde al legislador, en virtud del mandato del artículo 29 de la Constitución, y especialmente de su inciso segundo, fijar las formas propias de cada juicio, es decir, las normas procesales, y señalar el juez o tribunal competente para cada clase de asuntos. Por consiguiente, si el legislador dispone que, ante los árbitros habilitados por las partes en conflicto, se diriman asuntos propios del proceso de ejecución y establece las reglas de este proceso arbitral, en nada quebranta la Constitución." [55]

Resulta oportuno resaltar que la Corte invita a que se legisle y se establezcan las formas propias de un juicio ejecutivo arbitral para que sean los árbitros quienes tengan la competencia de conocer asuntos que se ventilarían en un proceso ejecutivo. De existir un proceso de estas características, la Corte anuncia que no vulneraria la Constitución, pero deja claro que, como actualmente el proceso arbitral es de naturaleza declarativa, no existe una regulación especial de un proceso ejecutivo para árbitros, por lo que debería efectuarse este tipo de regulación ${ }^{[56]}$.

En esta sentencia dos magistrados de la Corte salvan el voto y acogen lo resuelto en la sentencia de tutela T-057 de 1995, que resulta tener una fecha anterior a la sentencia de constitucionalidad C-294 antes citada. Esta sentencia de tutela resulta ser totalmente opuesta a lo consignado en la C-294 de 1995. En el salvamento de voto sustentan que el arbitraje solo puede tener por objeto asuntos particularmente limitados, por lo que si a los particulares se les atribuyera la facultad de disponer del poder coactivo se comprometería la paz y el orden público, así que, en su criterio, el cumplimiento coactivo de las obligaciones consagradas en títulos ejecutivos no es una potestad que la constitución le otorga a los árbitros ${ }^{[57]}$. Consideran que el ejercicio del poder de coerción y coacción es privativa y reservada al Estado, por lo que no podrían los árbitros autorizados por la voluntad de las partes conocer de los procesos de ejecución.

En el momento en que fue escrito este artículo, en el Senado de la República de Colombia se encuentra un proyecto de ley por medio del cual se crea el pacto arbitral ejecutivo, que tiene como finalidad que, mediante arbitraje, los particulares y entidades públicas puedan resolver y ejecutar cualquier tipo de obligación y controversia derivada de obligaciones que presten mérito ejecutivo. Aunque esta propuesta legislativa que apenas inicia ha generado muchos debates y posiciones encontradas que seguramente en un futuro serán conciliadas, resulta ser en ultimas la materialización de la invitación que realizó la Corte en la sentencia C-294 para que se legisle acerca de las formas propias de un juicio en torno al proceso ejecutivo arbitral al haber concluido que un proceso de esta naturaleza no vulnera la constitución.

\section{Los efectos económicos de los actos administrativos proferidos en ejercicio de facultades exorbitantes o excepcionales}

Con la entrada en vigencia de la Ley 80 de 1993 se estableció que sería la jurisdicción contencioso administrativa la competente para conocer de los conflictos surgidos de la actividad contractual del Estado. Sin embargo, con la influencia de los mecanismos alternativos de solución de conflictos se planteó la posibilidad de que particulares investidos de administrar justicia tuvieran competencia para conocer de este tipo de asuntos relacionados con el Estado. De esta manera, en la propia Ley 80 de 1993 se facultó a las partes, administración y particulares, para sustraer del conocimiento de la jurisdicción contenciosa los conflictos que, en virtud de la celebración, el desarrollo, la ejecución y la liquidación de los contratos estatales llegasen a surgir para que pudieran utilizar un mecanismo alterno tales como el arbitramento, la conciliación, la amigable composición y la transacción ${ }^{[58]}$. Es más, esta ley prohibió expresamente a las autoridades toda conducta que impida el uso de estos métodos alternativos de solución de conflictos cuando surjan diferencias en el contrato estatal. En conclusión, el Estado, como lo hacen los particulares, puede someter los desacuerdos surgidos con ocasión de un contrato donde es parte a la decisión de un tercero con la facultad de dirimir definitivamente la controversia, sin que se entienda afectado el interés público de los contratos estatales o la facultad de la administración para transigir. 
En la sentencia C-1436 de 2000 se establece que los árbitros pueden pronunciarse sobre la celebración, el desarrollo, la terminación y la liquidación del contrato siempre que sean sobre asuntos transigibles o disponibles como criterios de arbitrabilidad. No obstante, el Estado en materia contractual no se rige únicamente por los principios de la contratación entre particulares al aplicar la autonomía de la voluntad y la igualdad entre las partes contratantes, sino también por disposiciones extrañas a la contratación particular, según palabras de la propia Corte Constitucional ${ }^{[59]}$.

Las disposiciones extrañas a las que alude la Corte se conocen en Colombia como las llamadas cláusulas exorbitantes o excepcionales al derecho común, entendidas como una serie de prerrogativas que no ostentan los particulares, sino únicamente la entidad pública contratante en busca de la conservación y prevalencia del interés general implícitas en los contratos estatales. Estas facultades excepcionales de la administración le otorgan unos poderes para declarar la caducidad del contrato, su terminación, su modificación e interpretación unilateral como medidas extremas que debe adoptar el Estado después de agotar otros mecanismos para la debida ejecución del contrato. Esto se realiza con el fin de evitar no sólo la paralización de la ejecución del contrato, sino para hacer viable la continua y adecuada prestación del servicio que estos pueden comportar en atención al interés público implícito en estos contratos ${ }^{[60]}$. Estas facultades exorbitantes o excepcionales del estado no las otorga el contrato, por lo que no es una clase especial de contrato y tampoco su ejercicio puede ser objeto de convenio, la fuente de estos poderes está únicamente en la ley ${ }^{[61]}$.

Las cláusulas exorbitantes o excepcionales se hacen aplicables a los contratos administrativos a través de la manifestación de poder de la administración con la expedición de actos administrativos. El estudio de la legalidad del acto administrativo es de competencia exclusiva de los jueces en el contencioso administrativo y resulta indelegable a los particulares, así como el estudio sobre el ejercicio de las clausulas exorbitantes de la administración, al ser el juez natural de la legalidad de los actos de la administración ${ }^{[62]}$. La competencia de un árbitro no lo faculta para fallar sobre la legalidad de actos administrativos como los que declaran la caducidad de un contrato estatal, o su terminación unilateral, su modificación unilateral o la interpretación unilateral al ser asuntos de decisión exclusiva de la jurisdicción contencioso administrativa. En estos casos el Estado actúa en ejercicio de una función pública, en defensa del interés general que, por ser de orden público, no puede ser objeto de disponibilidad ${ }^{[63]}$.

La Corte reflexiona al plantear que, si la suspensión provisional de los efectos de los actos administrativos es un tema especial para la jurisdicción contencioso administrativo según el artículo 238 de la Constitución antes abordado, resulta excluida de igual forma para los árbitros la competencia para decidir sobre la legalidad de tales actos administrativos. Lo que no puede lo menos, mucho menos puede lo más. Es decir, si los árbitros no pueden pronunciarse sobre la suspensión provisional de los efectos de los actos administrativos, mucho menos podrán estudiar su legalidad.

Por otro lado, lo que sí puede ser sujeto a decisión de los árbitros es exclusivamente las consecuencias patrimoniales de estos actos administrativos. El aspecto económico de la decisión unilateral de la administración es una delimitación de competencia para los árbitros, en cambio la validez del acto administrativo es un pronunciamiento restringido para la jurisdicción contencioso administrativa. Las discusiones que se refieran únicamente al carácter patrimonial, aunque tengan causa en un acto administrativo, pueden ser de competencia de los árbitros, siempre y cuando no hagan un control de validez del acto administrativo por el que la administración ejerció tales poderes ${ }^{[64]}$. 


\section{Acciones de impugnación contra actos de asambleas, juntas de socios y juntas directivas en sociedades comerciales y la impugnación de actos de asamblea de la sociedad por acciones simplificada (SAS)}

En la lista de disposiciones derogadas expresamente por la Ley 1563 de 2012 en su artículo 118 está el artículo 194 del Código de Comercio. El antiguo artículo 194 del Código de Comercio disponía que las acciones de impugnación contra actos de asambleas, juntas de socios y juntas directivas debían ser ventiladas ante los jueces ordinarios permanentes de la rama judicial, a pesar de que se haya pactado cláusula compromisoria ${ }^{[65]}$. Dicho de otra manera, las acciones de impugnación antes mencionadas nunca podían ser de conocimiento de los árbitros, siempre eran competentes los jueces permanentes de la rama judicial. Sin embargo, con la derogatoria expresa citada se le abre la oportunidad a los árbitros para que conozcan de este tipo de controversias cuando exista un pacto arbitral de por medio.

Antes de la expedición del estatuto arbitral en el 2012, la Corte Constitucional en sentencia C-014 de 2010 declaró la exequibilidad de que las diferencias que se presentaran en una sociedad por acciones simplificada (SAS) pudieran ser conocidas por árbitros. Cabe resaltar que para esta época el tema era novedoso, porque no era permitido que las acciones de impugnación en una sociedad fueran conocidas por la justicia arbitral. La ley que creó las SAS, que luego fue reemplazado con el estatuto arbitral, abrió la posibilidad, aunque sea únicamente para las SAS en un principio, de que los árbitros conocieran controversias relacionadas con las acciones de impugnación contra actos de asambleas, juntas de socios y juntas directivas.

Acerca de la resolución de conflictos societarios en las SAS, en el artículo 40 se establece que

“las diferencias que ocurran a los accionistas entre sí, o con la sociedad o sus administradores, en desarrollo del contrato social o del acto unilateral, incluida la impugnación de determinaciones de asamblea o junta directiva con fundamento en cualquiera de las causas legales, podrán someterse a decisión arbitral o de amigables componedores, si así se pacta en los estatutos."[66]

A continuación, en el artículo 41 de la misma ley establece que para incluir en los estatutos de la sociedad la cláusula compromisoria se deberá contar con la aprobación del cien por ciento de las acciones suscritas, es decir, debe haber unanimidad de los socios en su intención de incluir el pacto arbitral en los estatutos. En efecto, basta con la oposición del titular de unas de las acciones para que no se pueda incluir en los estatutos la cláusula arbitral referida. Evento en el que no operaría la justicia arbitral y mantendría competencia la Superintendencia de Sociedades, según el artículo 24 del Código General del Proceso a prevención con los jueces civiles competentes.

La expresión de la voluntad en favor de la cláusula compromisoria obrante en los estatutos sociales de la SAS puede ocurrir en el momento de la constitución de la sociedad o en su reforma o con posterioridad a estas situaciones. Los accionistas de la sociedad SAS pueden aceptar la inclusión de la cláusula compromisoria en los estatutos de la sociedad, bien sea para su constitución o en una reforma estatutaria según lo explicado en los artículos 40 y 41 de la ley. Adicionalmente, el futuro socio, al examinar los estatutos de la sociedad en la cual va a ser parte, deberá percatarse de la existencia de esta cláusula, decidiendo ingresar o no. De ingresar a la sociedad libremente, el socio acepta libre y voluntariamente las reglas de los estatutos, incluyendo la cláusula compromisoria ${ }^{[67]}$. La característica de la voluntariedad del arbitraje se materializa de manera societaria cuando el socio manifiesta libremente su voluntad de hacer parte de una sociedad que tiene dentro de sus estatutos la cláusula compromisoria. 


\section{Asuntos laborales}

El Código Procesal del Trabajo y de la Seguridad Social fue proferido en el Decreto-Ley 2158 de 1948 con modificaciones introducidas por la Ley 712 de 2001 reguló el arbitramento en los artículos 130 a 143. Con la expedición del Decreto Extraordinario 1818 de 1998 en su artículo 172 y siguientes regulaba el arbitramento en materia laboral, pero simplemente compilaba lo que había sido regulado en el Código Procesal del Trabajo y de la Seguridad Social. Sin embargo, en el artículo 118 de la Ley 1563 de 2012 derogó expresamente la regulación que tenía el Decreto Extraordinario 1818 de 1998 sobre arbitraje laboral. A propósito de este punto, resulta oportuno mencionar la posición de la Corte Suprema de Justicia acerca de la vigencia del arbitraje en materia laboral luego de las derogaciones citadas. La Corte confirma la derogatoria antes explicada y menciona que en el estatuto arbitral no se regula el arbitraje laboral, por lo que concluye que

"las normas sobre arbitramento laboral contenidas en el Código Sustantivo del Trabajo y el Código Procesal del Trabajo y de la Seguridad Social mantienen su plena vigencia, al no haber sido derogadas expresa o tácitamente por la Ley 1563 de 2012 , muy a pesar de que el artículo 119 de la referida ley señale que regula íntegramente la materia de arbitraje.”[68]

Además de la discusión de la vigencia de las normas del arbitraje laboral del código de procedimiento laboral por la derogatoria del estatuto arbitral, es necesario resaltar que el concepto de arbitraje que se establece en materia laboral corresponde a una noción totalmente distinta a lo que se conoce como arbitraje en materia comercial, civil o en la que interviene el Estado o alguna de sus entidades. En materia laboral, el arbitraje puede ser obligatorio y voluntario, siendo el obligatorio inimaginable en materia comercial y civil y mucho menos cuando interviene el Estado. El arbitramento obligatorio laboral ${ }^{[69]}$ tiene como fin "la resolución de aquellas reivindicaciones con fines económicos y profesionales que pueden surgir entre los trabajadores con ocasión de la labor que les ha sido encomendada, los cuales se han denominado por la doctrina como conflictos económicos o de intereses" ${ }^{\text {[70] }}$. La regla general de voluntariedad del arbitramento se exceptúa en ciertos eventos indicados por el legislador, lo que autoriza el arbitramento obligatorio en las situaciones del artículo 452 del Código Sustantivo del Trabajo ${ }^{[71]}$ y uno nuevo adicional en el numeral 4 del artículo 448 del Código Sustantivo del Trabajo modificado por el artículo 1 de la Ley 1210 de $2008^{[72]}$.

Por su parte, el arbitramento voluntario ${ }^{[73]}$ busca que "la solución de 'los conflictos surgidos por razón de su vínculo ${ }^{\text {,74] }}$, es decir de aquellas controversias se originen directamente en el contrato de trabajo. Este tipo desacuerdos se denominan conflictos jurídicos, los cuales versan sobre la interpretación de un derecho ya existente ${ }^{[75]}$. De lo anterior se aprecia que la naturaleza de los conflictos que se resuelven en el arbitraje obligatorio y voluntario son diferentes ${ }^{[76]}$. Mientras que en el obligatorio la decisión que ha de tomarse se basa en criterios de justicia material por ser una decisión que involucra aspectos económicos de las partes, en el voluntario, el litigio ha de resolverse en derecho, al ser una diferencia en la aplicación de una norma legal o convencional ${ }^{[77]}$.

Finalmente, en el arbitraje voluntario se establece que la cláusula compromisoria sólo tendrá validez cuando conste en convención o pacto colectivo según el artículo 131 del Código Sustantivo del Trabajo. Lo que se convierte en una garantía para el trabajador pues no puede estar contenida ni en el contrato de trabajo, ni en ningún otro documento otorgado posteriormente, únicamente puede estar la cláusula compromisoria en convención o pacto colectivo. Existiendo la lucha en materia laboral del contrato laboral como contrato de adhesión y la preservación del equilibrio entre las partes, la imposición de una clausula de esta naturaleza podría restringir el acceso a la administración de justicia del trabajador motivado en la onerosidad del arbitraje y el eventual desistimiento de demandar al empleador. En efecto, evitar que renuncie el trabajador a la justicia ordinaria con la firma de una cláusula compromisoria es claramente una protección brindada por el legislador, de todas formas, si consta en convención o pacto colectivo se presume que su inclusión fue objeto de amplio 
debate sobre su conveniencia, por parte del sindicato o de los representantes de los trabajadores ${ }^{[78]}$. Para terminar, siempre existirá la posibilidad del compromiso para acudir al arbitraje a pesar de que el trabajador no esté sindicalizado o no lo cobije un pacto colectivo.

\section{Derecho de consumo}

Con la Ley 1480 de 2011 se expide el estatuto del consumidor en el que se regulan los derechos y las obligaciones surgidas entre los productores, proveedores y consumidores y la responsabilidad de los productores y proveedores, con el objetivo de proteger, promover y garantizar la efectividad y el libre ejercicio de los derechos de los consumidores. En el numeral 12 del artículo 43 de la Ley 1480 de 2011 eran consideradas cláusulas abusivas ${ }^{[79]}$ y por ello eran consideradas ineficaces de pleno derecho las que obligaran a los consumidores a acudir a la justicia arbitral, lo que generó la exclusión de la justicia arbitral en los conflictos de consumo. Sin embargo, esta disposición fue derogada expresamente por la Ley 1563 de 2012 en su artículo 118 y con ello le dio al arbitraje la bienvenida en el derecho de consumo, pues actualmente resultan ser válidos los pactos arbitrales, la cláusula compromisoria y el compromiso en materia de relaciones de consumo.

El arbitraje en el derecho de consumo tiene también fundamento normativo en los artículos 80 y 81 del Decreto 1829 de 2013 por el cual se regula el pacto arbitral en contratos de adhesión ${ }^{[80]}$. En un contrato de adhesión o de contenido predispuesto se podrá incluir el pacto arbitral como cláusula de opción debiendo ser clara, precisa e informarse explícitamente al celebrarse el contrato ${ }^{[81]}$. Esta norma de forma explícita indica que es materia de arbitrable todas las diferencias que surjan con referencia a la relación de consumo, en cualquiera de sus fases y/o aspectos originada en el negocio jurídico de adquisición de los bienes o prestación de servicios ${ }^{[82]}$. Por lo anterior, surge la posibilidad para que se pueda incluir una cláusula de opción de pacto arbitral dentro de un contrato de adhesión, en ningún momento se obliga al consumidor a acudir a la justicia arbitral, pero se le pone a su consideración si decide ventilar su controversia en la relación de consumo entre la justicia arbitral y la justicia ordinaria.

\section{Conclusiones}

Este artículo estudió la arbitrabilidad objetiva en Colombia que, luego de tener una visión histórica de la normativa, propuso un catálogo o lista de asuntos que no son arbitrables con origen en la propia ley, teniendo en cuenta varias decisiones que han proferido las cortes y la doctrina, además de haber comentado ciertas áreas o temas que, aunque sean arbitrables, actualmente han resultado ser controversiales para el conocimiento de los árbitros. La característica de la excepcionalidad propia del arbitraje tiene un vínculo que da origen al concepto de arbitrabilidad, que puede, a su vez, ser vista desde dos ópticas: la arbitrabilidad subjetiva y objetiva. Mientras la primera identifica a las personas que están facultadas para nombrar árbitros y someter su disputa a estas, la objetiva examina las materias o los temas que pueden ser susceptibles de arbitraje, teniendo en cuenta los asuntos que los jueces permanentes de la rama judicial deben siempre conocer.

La intención legislativa de incluir en la ley un catálogo de asuntos no arbitrables siempre ha existido, pero el tiempo nos ha mostrado que este listado en la ley podría truncar la evolución y dinámica jurisprudencial y legal que se necesita para la evolución de la arbitrabilidad objetiva. De todas formas, precisamente fruto de la libertad de la ley, se ha construido una lista de asuntos no arbitrables en Colombia que en ningún momento pretende ser limitativa ni mucho menos taxativa, pero que reflejan la evolución que ha tenido el legislador y las cortes en una construcción que no debe tener fin. En esta recopilación y estudio de asuntos o temas no arbitrables resaltamos la labor del legislador en el estado civil de las personas, suspensión provisional de los efectos de los actos administrativos, jurisdicción coactiva, las Zonas de Interés de Desarrollo Rural, 
Económico y Social (Zidres), al delimitar en la propia norma la restricción para que árbitros conozcan de estos asuntos. Adicionalmente, las providencias proferidas por las Cortes en Colombia han fijado la línea restrictiva para los tribunales arbitrales en temas como el conjunto de derechos mínimos de los trabajadores en materia laboral, orden público, soberanía nacional y orden constitucional, derechos morales de autor y ciertas acciones de nulidad en propiedad industrial, acciones de grupo o de clase, derechos de incapaces y derechos que se prohíbe a los titulares disponer.

Finalmente, a pesar de que el catálogo de asuntos no arbitrables en Colombia es relevante no solo para la competencia de los árbitros, sino también para el reconocimiento y ejecución de laudos en el arbitraje comercial internacional, igualmente se seleccionaron unos temas que, aunque son arbitrables, pudieron tener o haber tenido alguna controversia en cuanto a su arbitrabilidad que valió la pena destacar y estudiar. Asuntos como las acciones de impugnación contra actos de asambleas, juntas de socios y juntas directivas en sociedades comerciales, la impugnación de actos de asamblea de la Sociedad por Acciones Simplificada (SAS), asuntos laborales y derecho de consumo son temas que ha cambiado debido a la labor del legislador y que lo que en un principio no podía ser conocido por árbitros, tiempo después el legislador ha cambiado de parecer, convirtiéndolo en arbitrable como consecuencia de los cambios en la sociedad. De igual forma, las Cortes en su evolución también han mantenido y cambiado su posición en torno a la arbitrabilidad de ciertos temas como en los efectos económicos de los actos administrativos proferidos en ejercicio de facultades exorbitantes o excepcionales y el proceso ejecutivo. En definitiva, la arbitrabilidad objetiva no puede ser un tema congelado o inmóvil, necesita del cambio constante y evolución que le brinda la libertad legislativa, sin listas restrictivas de arbitrabilidad objetiva, y con la dinámica del legislador y de la jurisprudencia que refleje una sociedad cambiante y en construcción.

\section{Bibliografía}

Antonio María Lorca Navarrete, Algunas aportaciones sobre una nueva concepción de la naturaleza jurídica del arbitraje: su ámbito negocial-procesal, 43 Revista jurídica de la Universidad Interamericana de Puerto Rico, n. ${ }^{\circ}$ 1, 17-37 (2008).

Chistiam Ubeymar Infante Angarita, Arbitraje de consumo: aspectos generales e integración del contradictorio, Revista del Instituto Colombiano de Derecho Procesal, n. ${ }^{\circ}$ 42, 69-82 (2015). http://publicacionesicdp.com/index.php /Revistas-icdp/article/download/376/pdf

Código Civil colombiano [CCC]. Ley 57 de 1887.15 de abril de 1887 (Colombia).

Código de Comercio Colombiano [CCom.]. Decreto 410 de 1971.27 de marzo de 1971 (Colombia).

Código de Procedimiento Laboral colombiano [CPLC]. 24 de junio de 1948 (Colombia).

Consejo de Estado. Sala de lo Contencioso Administrativo. Sección Tercera. Proceso 4015 de 1994 (C. P. Enrique Gil Botero; 13 de abril de 1994).

Constitución Política de Colombia [Const.]. 7 de julio de 1991 (Colombia).

Corte Constitucional de Colombia. Sentencia C-014 de 2010 (M. P. Mauricio González Cuervo; 20 de enero de 2010).

Corte Constitucional de Colombia. Sentencia C-060 de 2001 (M. P. Carlos Gaviria Diaz; 24 de enero de 2001).

Corte Constitucional de Colombia. Sentencia C-098 de 2001 (M. P. Martha Victoria Sáchica Méndez; 31 de enero de 2001).

Corte Constitucional de Colombia. Sentencia C-1436 de 2000 (M. P. Alfredo Beltrán Sierra; 25 de octubre de 2000).

Corte Constitucional de Colombia. Sentencia C-155 de 1998 (M. P. Vladimiro Naranjo Mesa; 28 de abril de 1998).

Corte Constitucional de Colombia. Sentencia C-242 de 1997. (M. P. Hernando Herrera Vergara; 20 de mayo de 1997).

Corte Constitucional de Colombia. Sentencia C-294 de 1995 (M. P. Jorge Arango Mejía; 6 de julio de 1995).

Corte Constitucional de Colombia. Sentencia C-330 de 2000 (M. P. Carlos Gaviria Diaz; 22 de marzo de 2000). 
Corte Constitucional de Colombia. Sentencia C-330 de 2012 (M. P. Humberto Antonio Sierra Porto; 9 de mayo de 2012).

Corte Constitucional de Colombia. Sentencia C-349 de 2009 (M. P. Luis Ernesto Vargas Silva; 20 de mayo de 2009).

Corte Constitucional de Colombia. Sentencia C-378 de 2008 (M. P. Humberto Antonio Sierra Porto; 23 de abril de 2008).

Corte Constitucional de Colombia. Sentencia C-713 de 2008 (M. P. Clara Inés Vargas Hernández; 15 de julio de 2008).

Corte Constitucional de Colombia. Sentencia C-878 de 2005 (M. P. Alfredo Beltrán Sierra; 23 de agosto de 2005).

Corte Constitucional de Colombia. Sentencia SU-174 de 2007 (M. P. Manuel José Cepeda Espinosa; 14 de marzo de 2007).

Corte Constitucional de Colombia. Sentencia SU-995 de 1999 (M. P. Carlos Gaviria Diaz; 9 de diciembre de 1999).

Corte Constitucional de Colombia. Sentencia T-057 de 1995 (M. P. Eduardo Cifuentes Muñoz; 20 de febrero de 1995).

Corte Constitucional de Colombia. Sentencia T-299 de 1996 (M. P. Vladimiro Naranjo Mesa; 8 de julio de 1996).

Corte Suprema de Justicia. Sala de Casación Civil. Proceso 6094 de 2001 (M. P. Carlos Ignacio Jaramillo; 11 de mayo de 2001).

Corte Suprema de Justicia. Sala de Casación Laboral. Proceso 62867 de 2014 (M. P. Clara Cecilia Dueñas Quevedo; 12 de marzo de 2014).

Decisión 486 de 2000. Régimen común sobre propiedad industrial. 14 de septiembre de 2000. Artículos 75, 132 y 172.

Decreto 1818 de 1998 [Presidencia de la República]. Por medio del cual se expide el Estatuto de los mecanismos alternativos de solución de conflictos. 7 de septiembre de 1998.

Decreto 1829 de 2013 [con fuerza de ley]. Por el cual se reglamentan algunas disposiciones de las Leyes 23 de 1991, 446 de 1998, 640 de 2001 y 1563 de 2012. 27 de agosto de 2013. D.O. No. 48.895.

Édgar Iván León Robayo, Perspectiva y arbitrabilidad de la Convención Interamericana de Arbitraje Comercial Internacional, 11 Opinión Jurídica, n. ${ }^{\circ} 22,131-144$ (2012). http://www.scielo.org.co/pdf/ojum/v11n22/v11n 22a09.pdf

Enrique Pecourt García, La voluntad de las partes y su posible virtualidad en la determinación de la competencia judicial internacional, 17 Revista Española de Derecho Internacional, n. ${ }^{\circ}$ 1, 60-80 (1964). https://www.jstor.org/stabl e/44288345

Hernán Fabio López Blanco, Proceso arbitral nacional, Dupre Editores Ltda. (2013).

Ley 1258 de 2008. Por medio de la cual se crea la sociedad por acciones simplificada. 5 de diciembre de 2008. D.O. n. ${ }^{\circ} 47.194$.

Ley 1285 de 2009. Por medio de la cual se reforma la Ley 270 de 1996 Estatutaria de la Administración de Justicia. 22 de enero de 2009. D. O. n. ${ }^{\circ} 47.240$.

Ley 1480 de 2011. Por medio de la cual se expide el Estatuto del Consumidor y se dictan otras disposiciones. 12 de octubre de 2011. D.O. n. ${ }^{\circ} 48.220$.

Ley 1563 de 2012. Por medio de la cual se expide el Estatuto de Arbitraje Nacional e Internacional y se dictan otras disposiciones. 12 de julio de 2012. D.O. n. ${ }^{\circ} 48.489$.

Ley 1676 de 2013. Por la cual se promueve el acceso al crédito y se dictan normas sobre garantías mobiliarias. 20 de agosto de 2013. D.O. n. ${ }^{\circ} 48.888$.

Ley 1776 de 2016. Por la cual se crean y se desarrollan las zonas de Interés de desarrollo rural, económico y social, Zidres. 29 de enero de 2016. D.O. n. ${ }^{\circ} 49.770$.

Ley 270 de 1996. Considerando que la justicia es un valor superior consagrado en la Constitución Política que debe guiar la acción del Estado y está llamada a garantizar la efectividad de los derechos fundamentales, dentro del marco del Estado Social y Democrático de Derecho, y a lograr la convivencia pacífica entre los colombianos, y que dada la trascendencia de su misión debe generar responsabilidad de quienes están encargados de ejercerla. 15 de marzo de 1996. D.O. n. ${ }^{\circ} 42.745$. 
Ley 446 de 1998. Por la cual se adoptan como legislación permanente algunas normas del Decreto 2651 de 1991, se modifican algunas del Código de Procedimiento Civil, se derogan otras de la Ley 23 de 1991 y del Decreto 2279 de 1989, se modifican y expiden normas del Código Contencioso Administrativo y se dictan otras disposiciones sobre descongestión, eficiencia y acceso a la justicia. 8 de julio de 1998. D.O. n. ${ }^{\circ} 43.335$.

Ley 584 de 2000. Por la cual se derogan y se modifican algunas disposiciones del Código Sustantivo del Trabajo. 13 de junio de 2000. D.O. n. ${ }^{\circ} 44.043$.

Ley 80 de 1993. Por la cual se expide el Estatuto General de Contratación de la Administración Pública. 28 de octubre de 1993. D.O. n. ${ }^{\circ} 41.094$.

Mario Castillo Freyre \& Ricardo Vasquez Funze, Arbitraje: Naturaleza y Definicion, Derecho PUCP, n. ${ }^{\circ}$ 59, 273-284 (2006). http://revistas.pucp.edu.pe/index.php/derechopucp/article/view/3068

Néstor Humberto Martínez Neira, El pacto arbitral: Estatuto arbitral colombiano, Ed. Legis (2013).

Ramiro Bejarano Guzmán, Procesos declarativos, arbitrales y ejecutivos, Ed. Temis, (2019).

\section{Notas}

* Artículo de reflexión.

[1] Antonio María Lorca Navarrete, Algunas aportaciones sobre una nueva concepción de la naturaleza juridica del arbitraje: su ámbito negocial-procesal, 43 Revista jurídica de la Universidad Interamericana de Puerto Rico, n. ${ }^{\circ} 1,18$ (2008).

[2] Corte Constitucional de Colombia. Sentencia C-098 de 2001 (M. P. Martha Victoria Sáchica Méndez; 31 de enero de 2001).

[3] Ley 446 de 1998. Por la cual se adoptan como legislación permanente algunas normas del Decreto 2651 de 1991, se modifican algunas del Código de Procedimiento Civil, se derogan otras de la Ley 23 de 1991 y del Decreto 2279 de 1989, se modifican y expiden normas del Código Contencioso Administrativo y se dictan otras disposiciones sobre descongestión, eficiencia y acceso a la justicia. 8 de julio de 1998. D.O. n. ${ }^{\circ} 43.335$.

[4] Corte Constitucional de Colombia. Sentencia C-060 de 2001 (M. P. Carlos Gaviria Diaz; 24 de enero de 2001).

[5] Enrique Pecourt García, La voluntad de las partes y su posible virtualidad en la determinación de la competencia judicial internacional, 17 Revista Española de Derecho Internacional, n. ${ }^{\circ}$, 60-80 (1964).

[6] Corte Constitucional de Colombia. Sentencia C-330 de 2000 (M. P. Carlos Gaviria Diaz; 22 de marzo de 2000).

[7] Mario Castillo Freyre \& Ricardo Vasquez Funze, Arbitraje: naturaleza y definición, Derecho PUCP, n. ${ }^{\circ} 59,280$ (2006).

[8] Ley 1563 de 2012. Por medio de la cual se expide el Estatuto de Arbitraje Nacional e Internacional y se dictan otras disposiciones. 12 de julio de 2012. D.O. n. ${ }^{\circ} 48.489$, articulo 58.

[9] Constitución Política de Colombia [Const.]. Art. 29. 7 de julio de 1991 (Colombia).

[10] Corte Constitucional de Colombia. Sentencia C-060 de 2001 (M. P. Carlos Gaviria Diaz; 24 de enero de 2001).

[11] Corte Constitucional de Colombia. Sentencia C-330 de 2000 (M. P. Carlos Gaviria Diaz; 22 de marzo de 2000).

[12] Corte Constitucional de Colombia. Sentencia T-057 de 1995 (M. P. Eduardo Cifuentes Muñoz; 20 de febrero de 1995 ).

[13] Édgar Iván León Robayo, Perspectiva y arbitrabilidad de la Convención Interamericana de Arbitraje Comercial Internacional, 11 Opinión Jurídica, n. ${ }^{\circ} 22,135$ (2012).

[14] Corte Constitucional de Colombia. Sentencia SU-174 de 2007 (M. P. Manuel José Cepeda Espinosa; 14 de marzo de 2007).

[15] Édgar Iván León Robayo, op. cit., 136.

[16] Ley 270 de 1996. Considerando que la justicia es un valor superior consagrado en la Constitución Política que debe guiar la acción del Estado y está llamada a garantizar la efectividad de los derechos fundamentales, dentro del marco del Estado Social y 
Democrático de Derecho, y a lograr la convivencia pacífica entre los colombianos, y que dada la trascendencia de su misión debe generar responsabilidad de quienes están encargados de ejercerla. 15 de marzo de 1996. D.O. n.o 42.745.

[17] Esta disposición de la Ley 446, compilada luego en el Decreto 1818 de 1998, ha sido objeto de dos pronunciamientos de la Corte Constitucional. En la C-672 de 1999, se consideró que tal delimitación material de la competencia de la justicia arbitral podía hacerse en ley ordinaria, pues no constituía asunto reservado al legislador estatutario; y en la Sentencia C-098/01 se consideró que la disposición no violaba el artículo 116 de la Constitución, pues el legislador puede imponer límites materiales a los asuntos susceptibles de arbitramento.

[18] Decreto 1818 de 1998 [Presidencia de la República]. Por medio del cual se expide el Estatuto de los mecanismos alternativos de solución de conflictos. 7 de septiembre de 1998.

[19] Corte Constitucional de Colombia. Sentencia C-014 de 2010 (M. P. Mauricio González Cuervo; 20 de enero de 2010).

[20] Esta disposición fue declarada exequible en forma condicional por la Corte Constitucional, en sentencia C-713 de 2008 en lo referente a la configuración de las reglas de procedimiento a seguir "en el entendido de que las partes también deben respetar lo dispuesto por las leyes especiales que regulen los procedimientos arbitrales". Corte Constitucional de Colombia. Sentencia C-713 de 2008 (M. P. Clara Inés Vargas Hernández; 15 de julio de 2008).

[21] Ley 1285 de 2009. Por medio de la cual se reforma la Ley 270 de 1996 Estatutaria de la Administración de Justicia. 22 de enero de 2009. D. O. n. ${ }^{\circ} 47.240$.

[22] Ley 1563 de 2012. Por medio de la cual se expide el Estatuto de Arbitraje Nacional e Internacional y se dictan otras disposiciones. 12 de julio de 2012. D.O. n. ${ }^{\circ} 48.489$, articulo 1.

[23] Hernán Fabio López Blanco, Proceso arbitral nacional, Dupre Editores Ltda., 61 (2013).

[24] Hernán Fabio López Blanco, op. cit., 62.

[25] Nestor Humberto Martínez Neira, El pacto arbitral: Estatuto arbitral colombiano, Ed. Legis, 42 (2013).

[26] Corte Constitucional de Colombia. Sentencia C-294 de 1995 (M. P. Jorge Arango Mejía; 6 de julio de 1995).

[27] Corte Constitucional de Colombia. Sentencia C-242 de 1997. (M. P. Hernando Herrera Vergara; 20 de mayo de 1997).

[28] Corte Constitucional de Colombia. Sentencia C-098 de 2001 (M. P. Martha Victoria Sáchica Méndez; 31 de enero de 2001).

[29] Nestor Humberto Martínez Neira, op. cit., 40.

[30] Constitución Política de Colombia [Const.]. Art. 53.7 de julio de 1991 (Colombia).

[31] Corte Constitucional de Colombia. Sentencia SU-995 de 1999 (M. P. Carlos Gaviria Diaz; 9 de diciembre de 1999).

[32] Corte Constitucional de Colombia. Sentencia C-330 de 2000 (M. P. Carlos Gaviria Diaz; 22 de marzo de 2000).

[33] Corte Constitucional de Colombia. Sentencia C-1436 de 2000 (M. P. Alfredo Beltrán Sierra; 25 de octubre de 2000).

[34] Corte Constitucional de Colombia. Sentencia T-057 de 1995 (M. P. Eduardo Cifuentes Muñoz; 20 de febrero de 1995).

[35] Corte Constitucional de Colombia. Sentencia SU-174 de 2007 (M. P. Manuel José Cepeda Espinosa; 14 de marzo de 2007).

[36] Constitución Política de Colombia [Const.]. Art. 238.7 de julio de 1991 (Colombia).

[37] Constitución Política de Colombia [Const.]. Art. 236, 237 y 238.7 de julio de 1991 (Colombia).

[38] Corte Constitucional de Colombia. Sentencia C-1436 de 2000 (M. P. Alfredo Beltrán Sierra; 25 de octubre de 2000).

[39] Corte Constitucional de Colombia. Sentencia SU-174 de 2007 (M. P. Manuel José Cepeda Espinosa; 14 de marzo de 2007).

[40] Corte Constitucional de Colombia. Sentencia C-294 de 1995 (M. P. Jorge Arango Mejía; 6 de julio de 1995). 
[41] Íd.

[42] Corte Constitucional de Colombia. Sentencia C-155 de 1998 (M. P. Vladimiro Naranjo Mesa; 28 de abril de 1998).

[43] Código de Comercio Colombiano [CCom.]. Decreto 410 de 1971. Artículo 567.27 de marzo de 1971 (Colombia).

[44] Código de Comercio Colombiano [CCom.]. Decreto 410 de 1971. Artículo 580. 27 de marzo de 1971 (Colombia).

[45] Código de Comercio Colombiano [CCom.]. Decreto 410 de 1971. Artículo 596.27 de marzo de 1971 (Colombia).

[46] Decisión 486 de 2000. Régimen común sobre propiedad industrial. 14 de septiembre de 2000. Artículos 75, 132 y 172.

[47] Ley 1776 de 2016. Por la cual se crean y se desarrollan las zonas de Interés de desarrollo rural, económico y social, Zidres. 29 de enero de 2016. D.O. n. ${ }^{\circ} 49.770$.

[48] Corte Suprema de Justicia. Sala de Casación Civil. Proceso 6094 de 2001 (M. P. Carlos Ignacio Jaramillo; 11 de mayo de 2001).

[49] Hernán Fabio López Blanco, op. cit., 106.

[50] Corte Constitucional de Colombia. Sentencia C-294 de 1995 (M. P. Jorge Arango Mejía; 6 de julio de 1995).

[51] Corte Constitucional de Colombia. Sentencia T-299 de 1996 (M. P. Vladimiro Naranjo Mesa; 8 de julio de 1996).

[52] Código Civil Colombiano [CCC]. Ley 57 de 1887. Art. 15. 15 de abril de 1887 (Colombia).

[53] Corte Constitucional de Colombia. Sentencia C-294 de 1995 (M. P. Jorge Arango Mejía; 6 de julio de 1995).

[54] Ramiro Bejarano Guzmán, Procesos declarativos, arbitrales y ejecutivos, Ed. Temis, 517 (2019).

[55] Corte Constitucional de Colombia. Sentencia C-294 de 1995 (M. P. Jorge Arango Mejía; 6 de julio de 1995).

[56] En el artículo 78 de la Ley 1676 de 2013 se habilita el arbitraje para que conozca de los conflictos relacionados con la constitución, interpretación, prelación, cumplimiento, ejecución y liquidación de las garantías inmobiliarias. Ley 1676 de 2013. Por la cual se promueve el acceso al crédito y se dictan normas sobre garantías mobiliarias. 20 de agosto de 2013. D.O. n. ${ }^{\circ} 48.888$.

[57] Corte Constitucional de Colombia. Sentencia T-057 de 1995 (M. P. Eduardo Cifuentes Muñoz; 20 de febrero de 1995).

[58] Ley 80 de 1993. Por la cual se expide el Estatuto General de Contratación de la Administración Pública. 28 de octubre de 1993. D.O. n. ${ }^{\circ} 41.094$. Artículo 68.

[59] Corte Constitucional de Colombia. Sentencia C-1436 de 2000 (M. P. Alfredo Beltrán Sierra; 25 de octubre de 2000).

[60] Consejo de Estado. Sala de lo Contencioso Administrativo. Sección Tercera. Proceso 4015 de 1994 (C. P. Enrique Gil Botero; 13 de abril de 1994).

[61] Corte Constitucional de Colombia. Sentencia C-1436 de 2000 (M. P. Alfredo Beltrán Sierra; 25 de octubre de 2000).

[62] Constitución Política de Colombia [Const.]. Art. 236, 237 y 238.7 de julio de 1991 (Colombia).

[63] Corte Constitucional de Colombia. Sentencia C-1436 de 2000 (M. P. Alfredo Beltrán Sierra; 25 de octubre de 2000).

[64] Corte Constitucional de Colombia. Sentencia SU-174 de 2007 (M. P. Manuel José Cepeda Espinosa; 14 de marzo de 2007).

[65] Corte Constitucional de Colombia. Sentencia C-378 de 2008 (M. P. Humberto Antonio Sierra Porto; 23 de abril de 2008). En esta sentencia se declaró exequible en su momento el artículo 194 del Código de Comercio.

[66] Ley 1258 de 2008. Por medio de la cual se crea la sociedad por acciones simplificada. 5 de diciembre de 2008. D.O. n. 47.194.

[67] Corte Constitucional de Colombia. Sentencia C-014 de 2010 (M. P. Mauricio González Cuervo; 20 de enero de 2010).

[68] Corte Suprema de Justicia. Sala de Casación Laboral. Proceso 62867 de 2014 (M. P. Clara Cecilia Dueñas Quevedo; 12 de marzo de 2014). 
[69] Ley 584 de 2000. Por la cual se derogan y se modifican algunas disposiciones del Código Sustantivo del Trabajo. 13 de junio de 2000. D.O. n. ${ }^{\circ} 44.043$.

[70] Corte Constitucional de Colombia. Sentencia C-330 de 2012 (M. P. Humberto Antonio Sierra Porto; 9 de mayo de 2012).

[71] El artículo 452 del Código Sustantivo del Trabajo dispone que serán sometidos a arbitramento obligatorio 1) los conflictos colectivos de trabajo que se presenten en los servicios públicos esenciales y que no hubieren podido resolverse mediante arreglo directo; 2) los conflictos colectivos de trabajo cuando los trabajadores optaren por el arbitramento, conforme a lo establecido en el artículo 444 de dicho ordenamiento; y 3) los conflictos colectivos de trabajo de sindicatos minoritarios, siempre y cuando la mayoría absoluta de los trabajadores de la empresa no hayan optado por la huelga cuando esta sea procedente. Ley 584 de 2000. Por la cual se derogan y se modifican algunas disposiciones del Código Sustantivo del Trabajo. 13 de junio de 2000. D.O. n. ${ }^{\circ} 44.043$.

[72] El numeral 4 del artículo 448 del Código Sustantivo del Trabajo, modificado por el artículo 1 de la Ley 1210 de 2008, prevé otro evento en el cual procede el arbitramento obligatorio y ambas partes deben solicitar al Ministerio de la Protección Social la convocatoria de un tribunal: 4) cuando una vez terminada la etapa de arreglo directo no se haya logrado un acuerdo entre el empleador y los trabajadores, luego de ejercidos los buenos oficios por parte de la Comisión de Concertación de Políticas Salariales y Laborales. Ley 584 de 2000. Por la cual se derogan y se modifican algunas disposiciones del Código Sustantivo del Trabajo. 13 de junio de 2000. D.O. n. ${ }^{\circ} 44.043$.

[73] Código de Procedimiento Laboral colombiano [CPLC]. Articulo 130 y siguientes. 24 de junio de 1948 (Colombia).

[74] Corte Constitucional de Colombia. Sentencia C-349 de 2009 (M. P. Luis Ernesto Vargas Silva; 20 de mayo de 2009).

[75] Corte Constitucional de Colombia. Sentencia C-330 de 2012 (M. P. Humberto Antonio Sierra Porto; 9 de mayo de 2012).

[76] Íd.

[77] Corte Constitucional de Colombia. Sentencia C-878 de 2005 (M. P. Alfredo Beltrán Sierra; 23 de agosto de 2005).

[78] Corte Constitucional de Colombia. Sentencia C-878 de 2005 (M. P. Alfredo Beltrán Sierra; 23 de agosto de 2005).

[79] Ley 1480 de 2011. Por medio de la cual se expide el Estatuto del Consumidor y se dictan otras disposiciones. 12 de octubre de 2011. D.O. n. ${ }^{\circ}$ 48.220. El Artículo 42 indica que "son cláusulas abusivas aquellas que producen un desequilibrio injustificado en perjuicio del consumidor y las que, en las mismas condiciones, afecten el tiempo, modo o lugar en que el consumidor puede ejercer sus derechos."

[80] Chistiam Ubeymar Infante Angarita, Arbitraje de consumo: aspectos generales e integración del contradictorio, Revista del Instituto Colombiano de Derecho Procesal, n. ${ }^{\circ} 42,70$ (2015).

[81] Decreto 1829 de 2013 [con fuerza de ley]. Por el cual se reglamentan algunas disposiciones de las Leyes 23 de 1991, 446 de 1998, 640 de 2001 y 1563 de 2012. 27 de agosto de 2013. D.O. No. 48.895. Artículo 80.

[82] Decreto 1829 de 2013 [con fuerza de ley]. Por el cual se reglamentan algunas disposiciones de las Leyes 23 de 1991, 446 de 1998, 640 de 2001 y de 2012. 27 de agosto de 2013. D.O. No. 48.895. Artículo 81.

\section{Licencia Creative Commons CC BY 4.0}

Para citar este articulo/To cite this article: Juan Carlos Naizir Sistac, Arbitrabilidad objetiva: ¿Qué se puede y qué no se puede someter a arbitraje nacional según las fuentes colombianas de derecho?, 68 Vniversitas, n. ${ }^{\circ} 139$ (2019). https://doi.org/10.11144/Javeriana.vj139.aoqp 